\title{
A clinical observational study on second-trimester abortion
}

\section{Geetha Lakshmi R. ${ }^{1 *}$, Bommireddy Pranavi ${ }^{2}$, Neethu George ${ }^{3}$, K. Saraswathi ${ }^{4}$}

\author{
${ }^{1}$ Department of Obstetrics and Gynecology, Dhanalakshmi Srinivasan Medical College and Hospital, Perambalur, \\ Tamil Nadu, India \\ ${ }^{2}$ Department of Obstetrics and Gynecology, BSR Hospital, Atmakur, Nellore, Andhra Pradesh, India \\ ${ }^{3}$ Department of Community Medicine, Dhanalakshmi Srinivasan Medical College and Hospital, Perambalur, Tamil \\ Nadu, India \\ ${ }^{4}$ Department of Obstetrics and Gynecology, Sree Balaji Medical College and Hospital, Chromepet, Chennai, Tamil \\ Nadu, India
}

Received: 16 February 2020

Accepted: 24 February 2020

\section{*Correspondence:}

Dr. Geetha Lakshmi R.,

E-mail: glakshmii06@gmail.com

Copyright: (C) the author(s), publisher and licensee Medip Academy. This is an open-access article distributed under the terms of the Creative Commons Attribution Non-Commercial License, which permits unrestricted non-commercial use, distribution, and reproduction in any medium, provided the original work is properly cited.

\begin{abstract}
Background: Second-trimester abortion is an important component of the comprehensive women's health care. Data's regarding second-trimester abortion is still under-reporting. Though the percentage of induced secondtrimester abortion is low, its morbidity is higher than the first-trimester induced abortion. The abortion related mortality usually increases with the age of gestation.

Methods: A retrospective observational study was conducted in the department of obstetrics and gynecology at Sree Balaji Medical College and Hospital, Chennai, over a period of one year. The data were collected from the medical case records and we have analyzed on the epidemiology, etiologies, complications and the methods of secondtrimester abortion using statistical analysis.

Results: In this study, there was no standard regimen of mifepristone and misoprostol were used for second-trimester abortion. The dosages were varied based on the gestational age of pregnancy. As the gestational age progresses, the amount of misoprostol required for the induction of second trimester abortion decreases and the difference is statistically significant. There was no reported case of rupture uterus, but varied complications such as post-abortal hemorrhage, retained placenta, need for blood transfusion, uterine perforation and one maternal death were reported during the study period.

Conclusions: In order to reduce the morbidity and mortality of second trimester abortion, more policies and monitored services have to be rendered by the health system. Data regarding the second trimester abortion have to be improved.
\end{abstract}

Keywords: Abortion, Complications, Epidemiology, Etiology, Methods, Second-trimester

\section{INTRODUCTION}

Second-trimester abortion defines the miscarriages that are happening between 13 weeks and 26 weeks of gestation. ${ }^{1}$ It is an important component of the comprehensive women's health care. Various medical and social reasons such as late detection of pregnancy, detecting major congenital anomalies in the fetus, obstetric conditions such as preeclampsia, preterm premature rupture of membrane and fetal demise are the indications of second-trimester miscarriages. ${ }^{1}$ The data regarding second-trimester abortion is still underreporting. An abortion provider census states that, only $64 \%$ of them offers some services more than 12 weeks of gestation and only $23 \%$ of them offers services more than 20 weeks of gestation. ${ }^{1}$ 
Modern medical abortion of second-trimester miscarriage uses one or more of the following such as mifepristone, misoprostol, osmotic cervical dilators, Foley catheter insertion and oxytocin as inducing agents. Mifepristone followed by misoprostol in 24-48 hours later is the most effective regimen for second-trimester abortion with $91 \%$ efficacy within 24 hours of initiation of misoprostol with the lesser side effects of misoprostol alone. ${ }^{1}$ Surgical abortion by cervical softening and dilatation with osmotic dilators or misoprostol followed by dilatation and evacuation of the fetus is another method of termination of second-trimester pregnancy. Intact Dilatation and Evacuation is required, where the fetal anatomy is desired. Abdominal procedures such as hysterotomy or hysterectomy may require for some cases where the medical and surgical abortion fails. ${ }^{1}$ The methods such as intra or extra amniotic instillation of ethacridine lactate is outdated by WHO, which was previously used for termination of late second-trimester abortions, as it had adverse effects of long duration of labor, hospitalization for many days and may need for curettage. ${ }^{1}$

The mortality rate associated with abortion is 0.6 per $1,00,000$ legal induced abortions. Abortion related mortality usually increases with each week of gestation. It is 0.1 per $1,00,000$ procedures at 8 weeks of gestation and 8.9 per $1,00,000$ procedures at 21 weeks of gestation or later. ${ }^{1}$ Complications such as post abortal hemorrhage, cervical laceration, retained product of conception and infection can occur in both surgical and medical method of abortion. Uterine perforation is a complication of Dilatation and Evacuation and rupture uterus is a complication of medical abortion. ${ }^{1}$ Limited data is available for the usage of mifepristone for the abortion more than 14 weeks, but further studies is required for the same. Risk of uterine rupture occurring with prior caesarean delivery is same as that without previous caesarean section, so the guidelines suggests medical abortion particularly the usage of misoprostol for previous one caesarean delivery. ${ }^{1}$

\section{METHODS}

This was a retrospective clinical observational study conducted in the department of obstetrics and gynecology at Sree Balaji Medical College Hospital, Chromepet, Chennai over a period of one year from august 2015 to august 2016. The data were collected from the medical case records maintained in the hospital.

\section{Inclusion criteria}

- Patients who were all got admitted and treated for second-trimester abortions (i.e.) spontaneous or induced abortions between 12 weeks of gestation and 28 weeks of gestation

- Patients who got termination of pregnancy between 28 weeks and 32 weeks of gestation with fetus weighing less than $1 \mathrm{~kg}$ during the study period were included.

\section{Exclusion criteria}

- Patients having miscarriages before 12 weeks of gestation

- Patients who delivered or terminated the pregnancy after 28 weeks of gestation with the fetus weighing more than $1 \mathrm{~kg}$.

There were about 65 cases of second-trimester abortion reported during the study period. The following data such as age, parity, previous mode of delivery, gestational age of abortion, spontaneous or induced second-trimester abortion, indications for induced abortion, method of induction, (a) medical (total dose of mifepristone and total dose of misoprostol), (b) mechanical (Foley insertion), (c) surgical (dilatation and evacuation, hysterotomy), abortion induction - expulsion interval, post abortal complications if any were noted from the medical case records of the patients. Data's were collected and analyzed by using statistical methods.

\section{Statistical analysis}

The data were collected and enter into Microsoft excel and analyzed using statistical software. The descriptive statistics were mentioned using mean, median, frequencies, standard deviations and interquartile range. The inferential statistics were done using appropriate test like Chi square and Kruskal Wallis Test.

\section{RESULTS}

The age distribution of second trimester abortion patients and its statistics in this study are as shown in the Table 1 and 2 , with total no of patients $\mathrm{N}=65$, with the mean age of 25.95 , with the minimum age of 18 and the maximum age of 45 , with the median age of 25 and with standard deviation of 5.054 .

Table 1: Distribution of age in second trimester abortion.

\begin{tabular}{|ll|}
\hline Age distribution & Frequency \\
\hline$<=19$ years & 4 \\
\hline $20-24$ years & 25 \\
\hline $25-29$ years & 22 \\
\hline $30-34$ years & 10 \\
\hline $35-39$ years & 3 \\
\hline $40-44$ years & 0 \\
\hline$>45$ years & 1 \\
\hline
\end{tabular}

Table 2: Statistics of age distribution.

\begin{tabular}{|ll|}
\hline $\mathbf{N}$ & Age $(\mathbf{N}=\mathbf{6 5})$ \\
\hline Mean & 25.95 \\
\hline Median & 25.00 \\
\hline Standard deviation & 5.054 \\
\hline Minimum & 18 \\
\hline Maximum & 45 \\
\hline
\end{tabular}


The second trimester abortion is more frequent in primi gravida with $41.5 \%$ incidence, followed by second gravida, third gravida and fourth gravida with the incidence of $27.7 \%, 16.9 \%, 9.2 \%$ respectively and the incidence is least among the fifth gravida with $4.6 \%$.

Table 3: Marital status and consanguinity of marriage.

\begin{tabular}{|l|l|l|}
\hline Marital status & Frequency & Percent \\
\hline Unmarried & 6 & $9.2 \%$ \\
\hline Married & 59 & $90.8 \%$ \\
\hline Non-consanguineous & 50 & $76.9 \%$ \\
\hline II $^{\text {nd }}$ degree consanguinity & 5 & $7.7 \%$ \\
\hline III $^{\text {rd }}$ degree consanguinity & 10 & $15.4 \%$ \\
\hline Total & $\mathbf{6 5}$ & $\mathbf{1 0 0 \%}$ \\
\hline
\end{tabular}

Marital status and consanguinity of marriage in the study group are as shown in the Table 3. Among the 65 patients who had second trimester abortion, around $9.2 \%$ were unmarried and the remaining $90.8 \%$ were married women. The second trimester abortion was most common in non-consanguineous couple with the frequency of 50 people i.e. $76.9 \%$, followed by III-degree consanguineous couple with the frequency of $10(15.4 \%)$, and it was least common in II-degree consanguineous couple with the frequency of $5(7.7 \%)$.

Table 4: Distribution of previous mode of delivery in second trimester abortion.

\begin{tabular}{|c|c|c|}
\hline Previous mode of delivery & Frequency & Percent \\
\hline Primigravida & 27 & $41.5 \%$ \\
\hline $\begin{array}{l}\text { Previous normal vaginal } \\
\text { delivery }\end{array}$ & 23 & $35.4 \%$ \\
\hline Previous LSCS & 7 & $10.8 \%$ \\
\hline $\begin{array}{l}\text { Previous normal vaginal and } \\
\text { LSCS }\end{array}$ & 3 & $4.6 \%$ \\
\hline Only abortions & 5 & $7.7 \%$ \\
\hline Total & 65 & $100 \%$ \\
\hline
\end{tabular}

The distribution of previous mode of delivery, among the second trimester abortion in the study group is as shown in the Table 4. In this study, $41.5 \%$ patients are primigravida. In the remaining, $35.4 \%$ patients had previous normal vaginal delivery, $10.8 \%$ had either previous one or two caesarean deliveries, $4.6 \%$ had previous mode of both normal vaginal delivery and caesarean delivery and $7.7 \%$ had previous one or two miscarriage in the past.

In the study group 53 patients i.e., $18.5 \%$ had a previous history of abortion with or without previous vaginal or caesarean delivery or both and the remaining 12 patients i.e., $81.5 \%$ had no such previous history of abortion.

Among the 65 patients who had second trimester abortion, 44 patients had no other co-morbidities, 9 patients were hypothyroid, 2 patients had bronchial asthma, another 2 patients had type II diabetes Mellitus and another 2 patients had seizure disorder, 1 patient had anemia, another one had hyper-prolactinemia, another one was an old case of PT with Epilepsy complicating and another one was a psychotic disorder patient on treatment.

Table 5: Mode of onset and etiology of second trimester abortion.

\begin{tabular}{|lll|}
\hline Onset of abortion & Frequency & Percent \\
\hline Spontaneous & 18 & $27.7 \%$ \\
\hline Cervical incompetence & 3 & $4.61 \%$ \\
\hline Complete abortion & 7 & $10.8 \%$ \\
\hline Incomplete abortion & 8 & $12.3 \%$ \\
\hline Induced & 47 & $72.3 \%$ \\
\hline Congenital anomalies & 9 & $13.85 \%$ \\
\hline Oligo/anhydramnios & 4 & $6.15 \%$ \\
\hline Vesicular mole & 1 & $1.53 \%$ \\
\hline MTP & 8 & $12.3 \%$ \\
\hline Over counter drugs & 4 & $6.15 \%$ \\
\hline IUD & 3 & $4.61 \%$ \\
\hline Missed abortion & 16 & $24.61 \%$ \\
\hline Medical condition of mother & 2 & $3.08 \%$ \\
\hline Total & $\mathbf{6 5}$ & $\mathbf{1 0 0 \%}$ \\
\hline
\end{tabular}

Table 6: Method of induction of second trimester abortion.

\begin{tabular}{|l|ll|}
\hline Method of Induction & Frequency & Percent \\
\hline Spontaneous & 10 & $15.38 \%$ \\
\hline Medical & 39 & $60.02 \%$ \\
\hline $\begin{array}{l}\text { Combined (mechanical and } \\
\text { medical) }\end{array}$ & 12 & $18.46 \%$ \\
\hline Surgical D and E & 3 & $4.61 \%$ \\
\hline Hysterotomy & 1 & $1.53 \%$ \\
\hline Total & $\mathbf{6 5}$ & $\mathbf{1 0 0 \%}$ \\
\hline
\end{tabular}

Table 7: Gestational age distribution among secondtrimester abortion.

\begin{tabular}{|c|c|c|}
\hline Gestational age distribution & Frequency & Percent \\
\hline 12 weeks - 16 weeks & 39 & $60.0 \%$ \\
\hline 16 weeks +1 day -20 weeks & 13 & $20.0 \%$ \\
\hline 20 weeks +1 day -24 week & 6 & $9.2 \%$ \\
\hline 24 weeks +1 day -28 week & 4 & $6.2 \%$ \\
\hline $\begin{array}{l}>28 \text { weeks (fetus weighing } \\
\text { less than } 1 \mathrm{~kg} \text { ) }\end{array}$ & 3 & $4.6 \%$ \\
\hline Total & 65 & $100 \%$ \\
\hline
\end{tabular}

The mode of onset of second trimester abortion and its various etiologies in the study group are shown in the Table 5. In this study, 18 patients of the study group had spontaneous second trimester abortion which is about $27.7 \%$. Among the 18 patients, 3 patients had cervical incompetence, 7 patients had complete abortion and 8 patients had incomplete abortion, which required further either medical or surgical method of completion of 
termination of pregnancy. 47 patients had induced second-trimester abortion which is about $72.3 \%$. 16 patients had induced abortion due to missed abortion, 9 patients were induced due to lethal congenital anomalies, 8 patients had induced abortions due to various social reasons, 4 patients had induced themselves by the over counter drugs, 4 patients were induced due to severe oligohydramnios, 3 patients were induced due to intrauterine fetal demise, 2 patients were induced due to the medical condition of mother, of which one was psychotic and the another was status epilepticus and 1 patient was induced for partial molar pregnancy.

The various methods used for the induction of the second trimester abortion in this study group is shown in the Table 6. Among the 18 patients who had spontaneous onset of abortion in the study group, 10 patients had spontaneous second trimester abortion which doesn't require any further intervention, 2 patients required surgical dilatation and evacuation and the remaining 6 patients managed medically with misoprostol regimen.

Among the 47 patients who were induced for various etiologies, 12 patients were induced by both mechanical Foley insertions combined with misoprostol regimen, 33 patients were induced with combined mifepristone and misoprostol or misoprostol alone regimen, 1 patient of partial molar pregnancy required surgical $\mathrm{D}$ and $\mathrm{E}$, and another one required hysterotomy in whom where all the combined and medical methods failed.

The distribution of gestational age of second trimester abortion in this study is as shown in the Table 7. From the study, the second trimester abortion is most common between 12 weeks and 16 weeks of gestation with $60 \%$ occurrence, followed by $20 \%, 9.2 \%, 6.2 \%$ occurrence between 16 weeks +1 day to 20 weeks, 20 weeks +1 day to 24 weeks, 24 weeks +1 day to 28 weeks respectively, and it is least common after 28 weeks of gestation with 4 . $6 \%$ in occurrence (termination of pregnancy more than 28 weeks of gestation with the fetus weighing less than $1 \mathrm{~kg}$ was included in this study as second trimester abortion).

Table 8: Mifepristone dose used for second trimester abortion.

\begin{tabular}{|lll|}
\hline Mifepristone dosage used & Frequency & Percent \\
\hline Spontaneous abortion & 18 & $27.7 \%$ \\
\hline Mifepristone not given for IA & 23 & $35.4 \%$ \\
\hline $\begin{array}{l}200 \mathrm{mg} \text { of mifepristone given } \\
\text { for IA }\end{array}$ & 11 & $16.9 \%$ \\
\hline $\begin{array}{l}400 \mathrm{mg} \text { of mifepristone given } \\
\text { for IA }\end{array}$ & 1 & $1.5 \%$ \\
\hline $\begin{array}{l}600 \mathrm{mg} \text { of mifepristone given } \\
\text { for IA }\end{array}$ & 12 & $18.5 \%$ \\
\hline Total & $\mathbf{6 5}$ & $\mathbf{1 0 0} \%$ \\
\hline
\end{tabular}

IA: induced abortion.
Table 9: Statistics of total dose of Misoprostol in mg given for second-trimester abortion.

\begin{tabular}{|l|l|}
\hline $\mathbf{N}$ & Dose $(\mathbf{N}=\mathbf{6 5})$ \\
\hline Mean & 506.15 \\
\hline Median & 400.00 \\
\hline Mode & 0.00 \\
\hline Standard deviation & 488.02 \\
\hline Minimum & 0.00 \\
\hline Maximum & 2000 \\
\hline
\end{tabular}

The dose of mifepristone given for second-trimester abortion in this study is as shown in the Table 8. 27.7\% of patients had spontaneous second trimester abortion. In the remaining $73.3 \%$ of induced patients, $35.4 \%$ of the patients did not receive mifepristone to induce the second trimester abortion, $16.9 \%$ of the patient received $200 \mathrm{mg}$ of mifepristone for induction, $1.5 \%$ of the patient received $400 \mathrm{mg}$ of mifepristone for induction and 18.5 $\%$ of the patient received $600 \mathrm{mg}$ of mifepristone for the induction of second trimester abortion.

The statistics of total dose of misoprostol used for second-trimester abortion in this study is as shown in the Table 9. The mean value of total dose of misoprostol given for second-trimester abortion in this study is 506.15 $\mathrm{mg}$ with its median value of $400 \mathrm{mg}$, the mode is $0.00 \mathrm{mg}$ with the standard deviation of $488.02 \mathrm{mg}$. The minimum dose of misoprostol given in this study is $0.00 \mathrm{mg}$ with the maximum dose of misoprostol of $2000 \mathrm{mg}$ in divided doses.

The correlation between gestational age and the required dose of Misoprostol for induced second-trimester abortion is as shown in the Table 10. It shows that as the gestational week progresses, the total dose of Misoprostol required for induction of second trimester abortion decreases and the difference is statistically significant by Kruskal Wallis test $\mathrm{p}$ value 0.004 .

Table 10: Correlation between gestational age and required dose of Misoprostol in $\mathrm{mg}$ for secondtrimester abortion.

\begin{tabular}{|c|c|c|c|}
\hline $\begin{array}{l}\text { Gestational } \\
\text { age in weeks }\end{array}$ & $\begin{array}{l}\text { Misoprostol dose } \\
\text { median (IQR) in } \\
\text { mg }\end{array}$ & $\begin{array}{l}\text { Table } \\
\text { value }\end{array}$ & $\begin{array}{l}\text { p } \\
\text { value }\end{array}$ \\
\hline $\begin{array}{l}12 \text { weeks - } 16 \\
\text { weeks }\end{array}$ & $800(0,1000)$ & \multirow{5}{*}{15.04} & \multirow{5}{*}{0.004} \\
\hline $\begin{array}{l}16 \text { weeks }+1 \\
\text { day }-20 \text { weeks }\end{array}$ & $200(0,500)$ & & \\
\hline $\begin{array}{l}20 \text { weeks }+1 \\
\text { day }-24 \text { week }\end{array}$ & $100(0,500)$ & & \\
\hline $\begin{array}{l}24 \text { weeks }+1 \\
\text { day }-28 \text { weeks }\end{array}$ & $75(0,200)$ & & \\
\hline$>28$ weeks & $50(0,100)$ & & \\
\hline
\end{tabular}

$\mathrm{p}$ value is significant. Kruskal Wallis test. 
The induction-abortion interval noted in second trimester abortion either after the onset of pain in spontaneous abortion or after taking the first dose of misoprostol in induced abortion in the study group is as shown in the Table 11, and its statistics is shown in the Table 12. By statistics, the mean induction-abortion interval in this study is 15 hours and 35 minutes, with the median interval of 12 hours and with the mode of 6 hours. The minimum induction-abortion interval is 1 hour and 30 minutes and the maximum interval is 62 hours in this study.

Table 11: Induction abortion interval of secondtrimester abortion.

\begin{tabular}{|l|l|}
\hline Induction abortion interval & Frequency \\
\hline $0-6$ hours & 17 \\
\hline $6-12$ hours & 16 \\
\hline $12-18$ hours & 13 \\
\hline $18-24$ hours & 6 \\
\hline $24-30$ hours & 5 \\
\hline $30-36$ hours & 2 \\
\hline $36-42$ hours & 1 \\
\hline $42-48$ hours & 3 \\
\hline More than 48 hours & 2 \\
\hline
\end{tabular}

Table 12: Statistics of induction abortion interval of second trimester abortion.

\begin{tabular}{|l|l|}
\hline $\begin{array}{l}\text { Statistics of induction- } \\
\text { abortion interval }\end{array}$ & $\mathbf{N}=\mathbf{6 5}$ \\
\hline Mean & 15 hours and 35 minutes \\
\hline Median & 12 hours \\
\hline Mode & 6 hours \\
\hline Minimum & 1 hour and 30 minutes \\
\hline Maximum & 62 hours \\
\hline
\end{tabular}

Table 13: Complications during the second trimester abortion.

\begin{tabular}{|lll|}
\hline Complications & Frequency & Percent \\
\hline No complications & 48 & $73.8 \%$ \\
\hline Primary hemorrhage & 4 & $6.15 \%$ \\
\hline Drug induced fever & 2 & $3.07 \%$ \\
\hline Post-abortal pyrexia & 1 & $1.53 \%$ \\
\hline $\begin{array}{l}\text { Retained product of } \\
\text { conception }\end{array}$ & 1 & $1.53 \%$ \\
\hline Adherent placenta & 2 & $3.07 \%$ \\
\hline Blood transfusions & 10 & $15.38 \%$ \\
\hline Uterine perforation & 1 & $1.53 \%$ \\
\hline Maternal death & 1 & $1.53 \%$ \\
\hline
\end{tabular}

The various complications encountered during the second trimester abortion in the study group are listed in the Table 13. 48 patients in the study group didn't have any complications, 4 patients had primary post-abortal hemorrhage and 10 patients required one or more blood transfusions, 2 patients had adherent placenta which required manual removal of placenta, 1 patient had retained product of conception, 2 patients had drug induced fever, 1 patient had post abortal pyrexia, and 1 patient of vesicular mole had uterine perforation complicated with ileal perforation which required laparotomy with primary closure, and 1 patient who was unbooked second-trimester IUD was expired due to pulmonary embolism inspite of resuscitative measures.

\section{DISCUSSION}

Worldwide, second-trimester abortion constitutes about $10-15 \%$ of all induced abortions, but it is related to twothirds of abortion related complications and morbidities. ${ }^{2}$ Since last two decades, second-trimester induced abortion can be efficiently and safely performed by medical methods. Due to the various complications during second-trimester abortion it is always advised to have that in a center with operating facility and with blood transfusions and referral for transport if necessary. ${ }^{2}$

In India, statistics and studies on second-trimester miscarriage is scanty. Though there is a belief that second-trimester miscarriage is more common in India, the data so were collected does not emphasize the same. ${ }^{3}$ A study states that there were 3 illegal abortions for one legal abortion in rural area and 4-5 illegal abortion for one legal abortion in urban area. But it doesn't differentiate between the first and second-trimester abortions. ${ }^{3}$ Studies based on the gestational age of abortion states that, the first trimester abortion is commoner than the second-trimester abortion, but the morbidity is higher in second trimester abortion. ${ }^{3}$ It is estimated in 1964 before the MTP act, that for every 73 live births, 15 induced abortions were reported. ${ }^{4}$ A study in 1996 states that, $26 \%$ of 1717 abortion was secondtrimester abortion among which $3 \%$ was beyond 20 weeks. ${ }^{5}$ Statistics from Government of India in the year 2003 states that, $11 \%$ of abortion were happened in second-trimester.

A study in 2006, states that, the unintended pregnancy was the commoner reason for second-trimester abortion than the sex determination. ${ }^{6}$ In some region strong preference of male child with abandonment of girl child by finding the sex of fetus by ultrasound followed by second-trimester abortion was practiced. One study in Maharashtra states that second-trimester abortion is commoner in unmarried women rather than in the married women. ${ }^{7}$

According to MTP act 1971, for the termination of second-trimester pregnancy it requires two registered medical practitioners to confirm that there is a valid reason for termination. ${ }^{8}$ Most of the fetal anomalies cannot be diagnosed or confirmed in first trimester and due to the radiological inventions in antenatal detection of fetal anomalies, the therapeutic abortions based on these grounds have to be taken in second trimester or even in the third trimester and hence the increasing 
incidence of second trimester abortions in India. Some maternal health conditions, physical and mental, may also be identified in later pregnancy which warrants termination.

The MTP amendment Act in 2003, passed by Indian Parliament decentralizes the clinic registration process to the district level which facilitates the registration of private abortion clinics. ${ }^{9}$ After 45 years of legalization of MTP in India, there was about steady decline in sex ratio of female decided to track the pregnancy once it was confirmed in order to avoid the second-trimester abortion after the sex determination.

The standard method for second trimester abortion is medical abortion after the introduction of combined mifepristone and misoprostol regimen, where the mifepristone shortens the induction-abortion interval and also reduces the total dose of prostaglandin analogue requires for the second trimester abortion. The medical abortion was carried out up to 24 weeks successfully in various studies. ${ }^{10}$ In this study medical abortion was successful even up to 32 weeks. Due to the increased sensitivity of prostaglandins during second trimester, the dose of the same required for second trimester abortion is also less. ${ }^{11}$ This study also confirms the same.

A case series showed $2.5-11 \%$ of women required surgical intervention following medical abortion in second trimester of pregnancy. ${ }^{12}$ This study showed, $6.1 \%$ required surgical intervention for second trimester abortion following medical methods. Another study states that heavy bleeding which requires blood transfusion was only less than $1 \%$, but this study showed that, $15 \%$ of women required blood transfusion. ${ }^{13}$

Various many studies stated that the median inductionabortion interval is 5.9-6.6 hours. ${ }^{14,15}$ In this study it is about 15 hours and 35 minutes. This variation might be due to the factor that the standard combined mifepristonemisoprostol regimen had not followed in this study.

In this study, it was seen that no standard mifepristonemisoprostol regimen was given to the patients. The dosage of both mifepristone and misoprostol was varied according to the gestational age, but the success rate of medical abortion even up to 32 weeks was almost $93.85 \%$ without the complication of rupture uterus but other mentioned complications were encountered during the study period.

\section{CONCLUSION}

The health system has to reduce the mortality and morbidity from second-trimester abortion by delivering improvised and monitored services. In order to avoid second trimester abortion, all pregnancies have to be monitored from conception till delivery, more stringent action against quackery of sex detection has to be done. Greater information and data pertaining to the second- trimester abortions are required in order to motivate and to bring a change. Lastly, there is an urgent need for national policy which addresses safe abortion within the context of women's sexual and reproductive rights.

Funding: No funding sources Conflict of interest: None declared

Ethical approval: Not required

\section{REFERENCES}

1. The American College of Obstetricians and Gynecologists Women's Health Care Physicians Practice Bulletin Clinical Management Guidelines for Obstetrician - Gynecologists Number 135 June 2013 Reaffirmed; 2019. Available at: https://www.acog.org/-/media/Practice-Bulletins/ Committee-on-Practice-Bulletins

Gynecology/Public/pb135.pdf?dmc $=1 \&$ ts $=20190630$ T1739074502.

2. Gemzell-Danielsson K, Lalitkumar S. Second trimester medical abortion with mifepristonemisoprostol and misoprostol alone: a review of methods and management. Reprod Health Matters, 2008; 16:sup31:162-72.

3. Dalvie SS. Second Trimester Abortions in India, Reprod Health Matters. 2008;16:sup31:37-45.

4. Gupte M, Bandewar S, Pisal H. Abortion needs of women in India: a case study of rural Maharashtra. Reprod Health Matters. 1997;9:77-86.

5. Ganatra B, et al. Induced abortions in a rural community in Western Maharashtra: prevalence and patterns. Pune King Edward Memorial Hospital and Research Centre, 1996. Available at: https://www.ncbi.nlm.nih.gov/pubmed/12369334. Accessed on $16^{\text {th }}$ February 2020.

6. Pallikadavath S, Stones RW. Maternal and social factors associated with abortion in India: a population based study. Inter Family Plan Perspect. 2006;32(3):120-5.

7. Ravindran TKS. Gender gaps in research on abortion in India: a critical review of selected studies. Gender Reprod Health Res Initi. New Delhi: CREA. 2002:128.

8. The Medical Termination of Pregnancy Act, 1971. Available at: https://mohfw.gov.in/acts-rules-andstandards-health-sector/acts/mtp-act-1971. Accessed on $16^{\text {th }}$ February 2020.

9. Ministry of Health and Family Welfare notification; 2003. Available at: https://mohfw.gov.in/acts-rulesand-standards-health-sector/acts/mtp-regulations. Accessed on $16^{\text {th }}$ February 2020.

10. Unsafe abortion: global and regional estimates of the incidence of unsafe abortion and associated mortality in 2008. Available at: https://apps.who.int/iris/bitstream/handle/10665/445 29/9789241501118_eng.pdf;jsessionid=36BABD6A 044758930B8B3A35290E7865? sequence $=1$. Accessed on $16^{\text {th }}$ February 2020. 
11. Lalitkumar S, Bygdeman M, Gemzell-Danielsson K. Second trimester induced abortion: a review. Human Reprod Upd. 2007;13(1):37-52.

12. Armatage RJ, Luckas MJ. A randomized trial of 2 regimens for the administration of vaginal prostaglandins (gemeprost) for the induction of second trimester abortion. Australian and New Zealand J Obstet Gynecol. 1996;36(3):296-9.

13. Gemzell-Danielsson K, Östlund E. Termination of second trimester pregnancy with mifepristone and gemeprost: The clinical experience of 197 consecutive cases. Acta Obstet et Gynecol Scandina. 2000;79(8):702-6.

14. Ashok PW, Templeton A, Wagaarachchi PT, Flett GM. Midtrimester medical termination of pregnancy: a review of 1002 consecutive cases. Contracept. 2004;69(1):51-8.

15. Thong KJ, Baird DT. An open study comparing two regimens of gemeprost for the termination of pregnancy in the second trimester. Acta Obstet et Gynecol Scandina. 1992;71(3):191-6.

Cite this article as: Lakshmi $\mathrm{RG}$, Pranavi $\mathrm{B}$, George N, Saraswathi K. A clinical observational study on second-trimester abortion. Int J Reprod Contracept Obstet Gynecol 2020;9:1339-45. 